\title{
Investigation of the efficacy of transobturator tape (TOT) surgery in stress urinary incontinence
}

\author{
Mehmet Suhha Bostanci, Selcuk Ozden, Orhan Unal, \\ Arif Serhan Cevrioglu, Nermin Akdemir, Mustafa Albayrak \\ Sakarya University Faculty of Medicine, Training and Research Hospital, Sakarya, Turkey
}

\begin{abstract}
OBJECTIVE: To evaluate the safety and efficacy of transobturator vaginal tape (TOT) in the management women with stress urinary incontinence (SUI) and to analyze functional results and subjective cure rates at follow- up visits.

METHODS: Eighty-three consecutive women with SUI underwent TOT procedure. Data related to operative time, pre- and post-operative complications were collected. Subjective cure was defined as the absence of any urine loss on physical activity.
\end{abstract}

RESULTS: Mean age of the patients was 53.2 years, and $66.3 \%$ of the patients had pure SUI. The mean operative time was $24.96 \mathrm{~min}$ in cases of isolated SUI treatment. The mean hospital stay was $1.53 \pm 0.68$ days. At a mean follow-up of 32.8 months, the median subjective cure rate was 68.7 percent. Bladder injury ( $8.4 \%)$ was the only short and long term complication of this procedure.

CONCLUSION: TOT is a safe and effective procedure for SUI with a low rate of long- term complications. The short -term complication like bladder perforation may develop based on the experience of the surgeons or concomitant pelvic surgery.

Key words: Complication; stress urinary incontinence, transobturator vaginal tape (TOT).

S tress urinary incontinence (SUI) can be described as an involuntary urine loss, which has become a social problem. In this condition, increased intra-abdominal pressure causes urine leakage on effort, exertion, on sneezing or coughing when the support structures of the pelvic floor and the urinary system are stretched, damaged, or defective [1]. The prevalence of SUI in women has been estimated to be between $10 \%$ and $40 \%$, and it has a severe course in about $3 \%$ to $17 \%$ of women [2]. Factors that may increase the risk of developing incontinence include obesity, straining at stool, heavy manual labor, chronic obstructive pulmonary disease, and smoking [3,4]. Incidence increases with

Received: September 23, 2014 Accepted: December 08, 2014 Online: January 24, 2015

Correspondence: Dr. Mehmet Suhha BOSTANCI. Saglik Bakanligi Sakarya Universitesi Egitim Arastirma Hastanesi, Kadin Dogum Klinigi, Sakarya, Turkey. 
age $[3,4]$. Numerous surgical methods for stress incontinence have been described. To date, several tape procedures with various modifications have been introduced into female SUI treatment. Tension-free vaginal tape (TVT) was introduced for the treatment of SUI by Ulmsten more than a decade ago, with a success rate ranging from $85 \%$ to $95 \%[5,6]$. This procedure involves the insertion of two needles passed through the retropubic space blindly from vagina to abdomen or from abdomen to vagina. Cystoscopy is recommended to detect any perforation of the bladder or urethra [5]. In 2001, Delorme reported a transobturator vaginal tape (TOT) approach which consisted of placing a mesh through the obturator foramen behind the mid-urethra [7]. Surgical correction of SUI with TOT is the procedure of choice because of a shorter surgical time and a lower complication rate compared with TVT [8].

We focused on the morbidity and efficacy of the TOT procedure, including peri-, and post operative complications, and subjective results.

\section{MATERIALS AND METHODS}

This is a retrospective analysis on patients who underwent SUI surgery since 2009. Patients were operated on between January 2009 and September 2013 in the Gynecology and Obstetrics Department of Sakarya University Training and Research Hospital. Eighty-three patients were analyzed and examination results obtained during preoperative, perioperative, early postoperative periods, and at each follow- up visit were recorded. Findings were taken from patients files. Preoperatively, patients' medical history, physical examination findings, voiding diary notes, and their responses to the questions in the quality-oflife survey forms were evaluated. All participants had normal neurological findings. All had clinical signs of urethral hypermobility, with an abnormal cotton swab test (greater than 30 degrees) and a bladder capacity of at least $250 \mathrm{ml}$. All the patients received intravenous antibacterial prophylaxis (cefazolin, $2 \mathrm{~g}$ ) at the beginning of surgery, while no vaginal preparation was necessary the day before the surgery. Transobturator approach was performed as described by Delorme in 2001 using a curved tunneler inserted from the outside entrance point to adjust the tape without any tension [3]. Prolene light mesh (condensed monofilament non-absorbable polypropylene) was used as mesh material. A piece of polypropylene mesh (1.0$1.2 \mathrm{~cm}$ in width $20 \mathrm{~cm}$ in length) was cut by the surgeon from condensed monofilament non-absorbable polypropylene (TAHA Prolene Polypropylene mesh, Altaylar Bilim, Turkey). Patients were operated by several surgeons who routinely performed TOT procedures including residents in training as our department is an academic teaching centre. Routinely, cystoscopic examinations were not performed excepting the cases with complications of bladder injury. The incidence of perioperative and postoperative complications, febrile morbidity, analgesic requirements, and length of the postoperative hospital stay were recorded. Residual urine volume was evaluated after withdrawal of the Foley catheter. Voiding difficulties were defined as a residual urine volume of $150 \mathrm{~mL}$ or more, checked by postvoid catheterization. We recorded effectiveness and complications taking into account not only continence but overall well-being of the patients. Complications included adjacent organ injuries, hemorrhage, hematoma formation, urinary retention, and newly-developed urinary incontinence. Early postoperative complications were defined as those occurring during the first postoperative 7 days, and late postoperative complications as those that persisted or were diagnosed more than 7 days after the operation. Patients were clinically followed after one week, one month and one year after surgery. They were considered as cured when they did not present any stress urine leakage during a cough test with a full bladder and without the need of any continent pad during the past month. An improvement was registered when patients judged themselves as improved with less frequent use of urinary protective devices and/or pads during daily activities. Subjective cure was defined as women not experiencing any urine loss on physical activity. All other cases were recorded as subjective failures.

\section{RESULTS}

In this study, a total of 83 patients who underwent SUI were assessed. The median age of the patients 
was 53.20 years (range $30-74$ years) with a median body mass index (BMI) of $24.6 \mathrm{~kg} / \mathrm{m}^{2}(18-37)$. Characteristics of women undergoing TOT procedures were shown in Table 1 . The mean operative time was $24.96 \mathrm{~min}(17-35)$ in cases of isolated SUI treatment. Twelve patients $(14.5 \%)$ had previously undergone incontinence surgery including Burch colposuspension, and Kelly plication. Thirty-two patients had undergone combined vaginal procedures (hysterectomy, $\mathrm{n}=32$; rectocele repair, $n=13$; cystocele repair, $n=24$, and sacrospinofixation, $\mathrm{n}=21)$. All procedures were performed under general or regional anesthesia. No significant blood loss occurred in any cases. The mean hospital stay was $1.53 \pm 0.68$ days (range, $1-4$ days). No bleeding and no nerve, bowel, ureteral, or vascular injuries were reported. Bladder injury was observed in seven women $(8.4 \%)$, necessitating indwelling catheter for seven days. All bladder injuries occurred during the first pass of the tunneler. None of them occurred during passage of the mesh or during other simultaneously performed manipulations. Cystoscopic controls were performed in these patients and no surgical repair was made because of the presence of a small perforation site less than $1 \mathrm{~cm}$. None of the patients had long term complications like urethral erosion, vaginal erosion or extrusion. Median followup period was 32.86 months (range, 6-52 months). The overall subjective cure rate was $68.7 \%$. Patients' complaints resolved in $27.7 \%$ of the study subjects. Only $3.6 \%$ of the patients indicated persistence of complaints after the TOT procedure (Table 2).

\section{DISCUSSION}

The main goal of the surgical treatment of SUI is to restore a perfect continence with minimal morbidity. Surgical procedures to remedy stress incontinence generally aim to lift and support the urethrovesical junction but in the last decade the emphasis has been on suburethral support at the mid urethral level [9]. Although it is effective and easy to perform, the retropubic placement of suburethral TVT has been associated with a number of periand post-operative complications including mesh erosion, urinary retention, de novo overactive blad-
TABLE 1. Characteristics of women undergoing TOT procedure

Mean Age (year) $\pm S D$

$53.20 \pm 10.19$

Mean parity \pm SD

$3.65 \pm 1.45$

$\mathrm{BMI} \pm \mathrm{SD}$

$24.66 \pm 4.11$

Stress Incontinence

$66.3 \%$

Mixed Incontinence

$33.7 \%$

Mean time of Incontinence (year) $\pm S D$

$7.11 \pm 6.12$

TABLE 2. Characteristics of TOT operation and subjective cure rates

Mean operative time $(\mathrm{min}) \pm \mathrm{SD}$

$24.96 \pm 3.59$

Mean hospital stay (day) \pm SD

$1.53 \pm 0.68$

Complications

No complication

$91.6 \%$

Bladder Injury

$8.4 \%$

Mean follow-up (month) \pm SD

$32.86 \pm 14.87$

Subjective cure rates

No cure

$3.6 \%$

Improvement

$27.7 \%$

Cure

$68.7 \%$

der, vascular injury, bowel and bladder injuries [10, 11]. Most complications appear to be related to the blind upward vaginal passage of the trocars into the retropubic space $[7,9]$.

Delorme et al. described the transobturator approach as an excellent alternative to the retropubic approach that reduces complications [7]. Shortly after the introduction of the transobturator approach a similar operation was described which allows the passage of a tape through the obturator foramina, from inside to outside [12]. In our cases, trocars were placed from outside- in as described by Delorme. Subjective cure is usually regarded as the absence of incontinence during cough stress test.

Surgical correction of SUI with TOT is the procedure of choice because of its shorter surgical time and a lower complications rate compared with TVT. According to published data any significant 
difference between TOT and TVT as for the subjective cure rates does not exist during midterm follow-up [13]. Angioli reported a $62 \%$ subjective cure rate in 37 patients during 5 years after TVT [14]. Houwert reported a cure rate of $72 \%$ in 93 patients after TVT and 69\% after TOT at 2-4 years [15]. In our cases cure rate of $68.7 \%$ and improvement rate of $27.7 \%$ were detected. We found similar satisfaction rates with other studies but subjective cure rate detected in our study was a bit lower in comparison with other studies $[9,14,16,17]$.

Bladder perforation occurred in $15 \%$ of women in this report which was higher than that reported by others. All our patients were treated with an indwelling catheter for seven days and no long- term complications were encountered. Concomitant pelvic surgery may have contributed to higher bladder injury rate. The complications like nerve, bowel, urethral, or vascular injuries did not occur. Also long- term complications like urethral erosion, vaginal erosion, or vaginal extrusion did not develop during the follow-up period.

In conclusion, short-term complication of bladder perforation occurs at an unexpectedly high rate. This might be related to the technique as well as the experience of the surgeons or concomitant pelvic surgery. TOT procedure is a very effective treatment of SUI with low morbidity. The fact that the tape provides more firm support than a suspension of the urethra might explain the low rate of complications.

Conflict of Interest: No conflict of interest was declared by the authors.

Financial Disclosure: The authors declared that this study has received no financial support.

\section{REFERENCES}

1. Haylen BT, de Ridder D, Freeman RM, Swift SE, Berghmans $\mathrm{B}$, Lee J, et al. An International Urogynecological Association (IUGA)/International Continence Society (ICS) joint report on the terminology for female pelvic floor dysfunction. Neurourol Urodyn 2010;29:4-20.

2. Botlero R, Urquhart DM, Davis SR, Bell RJ. Prevalence and incidence of urinary incontinence in women: review of the literature and investigation of methodological issues. Int J Urol 2008; 15:230-4. CrossRef
3. Foldspang A, Mommsen S, Lam GW, Elving L. Parity as a correlate of adult female urinary incontinence prevalence. J Epidemiol Community Health 1992;46:595-600. CrossRef

4. Kirss F, Lang K, Toompere K, Veerus P. Prevalence and risk factors of urinary incontinence among Estonian postmenopausal women. Springerplus 2013;2:524. CrossRef

5. Ulmsten U, Henriksson L, Johnson P, Varhos G. An ambulatory surgical procedure under local anesthesia for treatment of female urinary incontinence. Int Urogynecol J Pelvic Floor Dysfunct 1996;7:81-6. CrossRef

6. Nilsson CG, Falconer C, Rezapour M. Seven-year follow-up of the tension-free vaginal tape procedure for treatment of urinary incontinence. Obstet Gynecol 2004;104:1259-62. CrossRef

7. Delorme E. Transobturator urethral suspension: mini-invasive procedure in the treatment of stress urinary incontinence in women. [Article in French] Prog Urol 2001;11:1306-13. [Abstract]

8. Ward KL, Hilton P; UK and Ireland TVT Trial Group. Tensionfree vaginal tape versus colposuspension for primary urodynamic stress incontinence: 5-year follow up. BJOG 2008;115:226-33.

9. Barber MD, Kleeman S, Karram MM, Paraiso MF, Walters MD, Vasavada S, et al. Transobturator tape compared with tensionfree vaginal tape for the treatment of stress urinary incontinence: a randomized controlled trial. Obstet Gynecol 2008;111:611-21.

10. Peyrat L, Boutin JM, Bruyere F, Haillot O, Fakfak H, Lanson Y. Intestinal perforation as a complication of tension-free vaginal tape procedure for urinary incontinence. Eur Urol 2001;39:603-5.

11. Hermieu JF, Messas A, Delmas V, Ravery V, Dumonceau O, Boccon-Gibod L. Bladder injury after TVT transobturator. [Article in French] Prog Urol 2003;13:115-7. [Abstract]

12. de Leval J. Novel surgical technique for the treatment of female stress urinary incontinence: transobturator vaginal tape insideout. Eur Urol 2003;44:724-30. CrossRef

13. Park YJ, Kim DY. Randomized controlled study of MONARC vs. tension-free vaginal tape obturator $\left(\mathrm{TVT}^{\circ} \mathrm{O}^{\circ}\right)$ in the treatment of female urinary incontinence: comparison of 3-year cure rates. Korean J Urol 2012;53:258-62. CrossRef

14. Angioli R, Plotti F, Muzii L, Montera R, Panici PB, Zullo MA. Tension-free vaginal tape versus transobturator suburethral tape: five-year follow-up results of a prospective, randomised trial. Eur Urol 2010;58:671-7. CrossRef

15. Houwert RM, Renes-Zijl C, Vos MC, Vervest HA. TVT-O versus Monarc after a 2-4-year follow-up: a prospective comparative study. Int Urogynecol J Pelvic Floor Dysfunct 2009;20:1327-33.

16. Abdel-fattah M, Ramsay I, Pringle S, Hardwick C, Ali H. Evaluation of transobturator tapes (E-TOT) study: randomised prospective single-blinded study comparing inside-out vs, outside-in transobturator tapes in management of urodynamic stress incontinence: short term outcomes. Eur J Obstet Gynecol Reprod Biol 2010;149:106-11. CrossRef

17. But I, Faganelj M. Complications and short-term results of two different transobturator techniques for surgical treatment of women with urinary incontinence: a randomized study. Int Urogynecol J Pelvic Floor Dysfunct 2008;19:857-61. CrossRef 